UCRL --102576

DE91 000813

\title{
Uses of Fabry-Perot Velocimeters in Studies of High Explosives Detonation
}

R. D. Breithaupt and C. M. Tarver

This paper was submitted to the SPIE's 1990

International Symposium on Optical and Optoelectronic Applied Sciences Meeting San Diego, Ca July 9-13, 1990

This is a preprint of a paper intended for publication in a journal or proceedings. Since changes may be made before publication, this preprint is made available with the understanding that it will not be cited or reproduced without the permission of the author.

August 27, 1990 \section{ing}




\section{DISCIAIMFR}

This document was prepared as an account of work sponsored by an agency of the United States Government. Neither the United States Government nor the University" of California nor any of their employees, makes any warranty, express or implied, or assumes any legal liability or responsibility for the accuracy, completeness, or usefulne'ss of any information, apparatus, product, or process disclosed, or represents that its use would not infringe privately owned rights. Reference herein to any specific commercial products, process, or service by trade name, Irademark, manufacturer, or otherwise, does not necessarily constitute or imply its endorsement, recommendation, or favoring by the United States Government or the University of Callfornia. The views and opinions of authors expressed herein do not necessarily state or reflect those of the United States Government or the University of Catifornia, and shall not be used for advertising or product endorsement purposes. 
Uses of Fabry-Perot velocimeters in studies of high explosives detonation

\author{
R. D. Breithaupt and C. M. Tarver \\ Lawrence Livermore National Laboratory \\ Chemistry and Materials Science Department, Livermore, CA 94550
}

\title{
INTRODUCTION
}

The Fabry Perot has become an important and valuable tool by which explosive performance information can be obtained relatively easily and inexpensively. Principle uses of the Fabry Perot have been free surface, and particle velocity measurements in one dimensional studies of explosive performance. In the cylinder test, it has been very useful to resolve early wall motions.

We have refined methods of characterizing new explosives i.e. equation of state, C-J pressure, via the cylinder shot, flat plate, and particle velocity technicues. All of these use Fabry Perot as one of the principle diagnostics. Each of these experimental techniques are discussed briefly and some of the results obtained. Modeling developed to fit Fabry-Perot results are described along with future testing.

\section{EXPERIMEN'TAL}

Nanosecond time resolution detonation studies can be routinely carried out with the use of FabryPerot. 'Previous researchers have used several techniques to study detonation flow. Hayes and Erickson 1,9 used thin gauges or foils sandwiched between layers of explosive. Large magnets were required to produce fields in which the foil position was driven by the detonation front. Manganin pressure gauges have also been used to obtain pressure versus time in explosives for some time as well as ultra-fast arrival pins which measure wave front velocities.

Using Fabry-Perot or VISAR laser interferometry one can measure velocity directly with a minimum disturbance to the detonation flow. It is a non contact method and records velocity directly and continually, not at time of arrival points as with pins. Experimental assembly is easily accomplished whereas other methods require precise and careful placement of wires or gauges within layers of explosive.

We have established a method, whereby explosives can be very carefully characterized with only a dozen experiments using Fabry-Perot. They are the following:

$$
\begin{aligned}
& \text { - Duplicate cylinder experiments. } \\
& \text { - } \quad \text { Six head-on flat plate push experiments. } \\
& \text { Four particle velocity experiments. }
\end{aligned}
$$

\section{FABRY PEROT SYSTEMS}

We have several Fabry Perot systems available for explosive performance studies. A schematic lilyout of our present system is shown in Figure 1. Fabry systems were first installed into our Site 30) explosive firing bunkers. They have evolved to the present techniques of using laser amplifiers, fiber optics, and splitting the beams for recording two velocities from the same experiment. ${ }^{2}$

Fabry Perot velocimeters have also been used on large, $10(0 \mathrm{~mm}$ diameter guns, which can accelerate projectiles over $2.0 \mathrm{~mm} / \mathrm{us}$. These Fabry systens usually look at the rear surfaces of explosives or metal plates which were impacted by a pliner projectile.

\footnotetext{
* Work performed under the auspices of the U.S. Department of Energy by the Lawrence Livemore National Laberatory under contract No, W-7405-ENG-48.
} 
An other Fabry Perot system has been built to support two separate shot tanks. Explosive capacity of one tank is $100 \mathrm{gms}$ and the other is capable of firing $350 \mathrm{gms}$. One Fabry-Perot system supports either shot tank by simply moving a single mirror. Shots in these tanks are relatively small and inexpensive to conduct and several experiments can be done on a single day. An electric gun ${ }^{10}$ is used to fire shots which reduces the amount of explosive in a tank. By using different flyer velocities and slapper thicknesses we can taylor impact conditions for ignition studies.

\section{FREE SURFACE STUDIES}

Thin metal plates are bonded to the top of the explosive and the accelerition of the plates is recorded with the Fabry- Perot. Shown in Figure 2 is a liyout of typical shot assembly. We initially used copper to measure free surface velocities of explosives. The thicker, $0.5 \mathrm{~mm}$, copper plates spalled. Tantalum has been successfully used without spalling and continues to be our primary metal for free surface measurements.

We have standardized tantalum plate to explosive thickness as shown in Table 1. Specimens are 25.4 $\mathrm{mm}$ in diameter and weigh 5,10, and 15 grams, respectively.

TABLE 1

$\begin{array}{lc}\frac{\text { Plate Thickness }}{0.102 \mathrm{~mm}} & \frac{\text { HE Thickness }}{6.0 \mathrm{~mm}} \\ 0.254 & 6.0 \\ 0.508 & 12.0\end{array}$

The $(0.102 \mathrm{~mm}$ thick plate is thin enough that the reaction zone characteristically will accelerate the thin plate to a higher initial jump off and a much steeper pull-back than thicker plates.

\section{PARTICLE VELOCITY MEASUREMENTS}

A detonation front can be observed as it exits the explosive into a material of the same or very nearly the same impedance. By impedance matching, the structure of the front is undisturbed and can be observed. We have successfully used $\mathrm{NaCl}$ and LiF crystals to conduct these measurements. Shown in Figure 3 is a schemitic of the experimental arrangement.

The crystals are coated with $4(0)()$ angstroms of gold on one surface. The explosive specimens are lapped flat to obtain intimate contact between the crystal and the explosive. The gold surface is put next to the explosive, the laser beam goes through the crystal and reflects off of the gold. Wackerle' has measured the index of refraction of several materials. The two crystals we are using have a constant correction over a large pressure range. A typical record is shown in Figure 4.

\section{CYLINDER TESTS}

The traditional cylinder test used only streak cameras to measure detonation product expansions of explosives. Results between explosives were compared at large expansions; R-R() of $19 \mathrm{~mm}$. Early time results were of poor quality for two reasons. Magnification of the cylinder did not allow high resolution of the first few microseconds of expansion. Secondly, air shock produced by the copper wall for the first microseconds made analysis difficult. ${ }^{8}$

The addition of the Fabry Perot now allows for accurate and precise moasurements of the early wall nucition. When shocked the wall angle jumps 5 to 10 degrees from normal depending upon the explosive 
being tested. We have obtained very good results by first positioning the beam at 7 degrees and collecting a minimum return from a defuse spot on the cylinder.

The Fabry Perot wall velocity from a cylinder experiment was $3 \%$ to $4 \%$ below that of the streak cameras, The additional velocity from the streak cameras can be accounted for it one adds the motion due to the detonation wave moving up the tube to the radial expansion given by the expanding explosive products. By adding this phase velocity we obtain very good agreement between techniques.

\section{REACTIVE FLOW MODELING}

It has become clear from the flat plate and particle velocity measurements that old equations of state do not fit some results. This is especially true for explosives which have a finite time duration reaction zone. For some experimental techniques the reaction zone is two narrow to be observed. With the resolution of the Fabry-Perot, approximately 10 nano seconds, shown in Figgure 5. Reaction zones are easily seen, as Hydrodynamic computer modeling is now required to handle the two phases of a detonation front. Firstly the spike which has a very high pressure and falls to a point which has been generally called the C-J |ChapmanJouguet], and then the expanding detonation products. ${ }^{4}$ In order to handle both we now use Reactive Flow modeling to handle both rates as shown in Figure 6 .

\section{COMPLETED EXPLOSIVE STUDIES}

With the use of the Fabry-Perot we have refined Equation of States for several explosives. Some of the explosives completed are PETN, TNT, LX-17, I.X-()4, PBX-94()4, and LX-14. We have repeated cylinder shots with Fabry-Perot and conducted both ilat plate and particle velocity testing on these materials.

Use of the Fabry Perot has given chemists the ability to resolve chemical reactions during detonation which has been very difficult to do in the past. By conducting particle velocity tests one can determine carbon formation during the detonation product expansion. Tests were conducted to observe evidence of carbon formation in the detonation products of three explosives. PETN which does not form carbon and TNT and LX-17 which have carbon in their products were tested. ${ }^{5}$ Explosives with multiple components have also been tested, such as Baratol' in which the percentage of barium nitrate reacting was determined. Solid propellants have also been studied for their multicomponet nature. They usually exhibit large reaction zones and have large failure diameters. Typically they contain an explosive component, rubbery binder, aluminum, energetic liquid, and an oxidizer. Several of these mixtures have been successfully characterized.

Presently we are conducting a series of tests on three composite explosives to determine how aluminum reacts. For the fïrst test series we ate using 5 micron spherical alluminum. The Table below lists the compositions tested. From these studies one can determine the optimum weight percentage of aluminum for the best performance.?

\section{Table 4}

Composition
PETN/Aluminum
TN'T/Aluminum
RDX/Aluminum

\author{
Wt.\% Aluminum \\ $5,1(0,2(), 3(), 40$ \\ $5,1(0,20,3(), 40$ \\ $5,10,20,3(0,40$
}

Lastly, one of the most important uses of the Fabry Perot has been the characterization of new explosives. These are nomally formulated in very limited quantities of materiai. By using the electric gun and $25.4 \mathrm{~mm}$ diameter samples which weigh less than 20 grams each we can obtain free surface velocity and particle velocity information on qualities less the $100 \mathrm{gms}$ of material. From these early tests one can determine if larger and more expensive tests should be conducted. 


\section{FUTURE STUDIES}

The composite explosive series using the 5 micron spherical aluminum will soon be completed. The next phase of the project will be to use flake aluminum, which has a much larger reactive surface area than the spherical particles. Then we will add an oxidizer such as ammonium perchlorate or ammonium nitrate.

Some new high density energetic explosives are being scaled up presently. The first test series will be done using flat plate and particle velocity measurements as per Table 1 . If they have good performance we will continue testing in larger experiments such as cylinder shots.

A new experimental technique we wish to pursue is to obtain both sideways wall velocity, as in the cylinder test, as well as head on, as in the hat plate test from the same experiment. This could be done using fiber optics and splitting the beam. From this one experiment we can measure large expansions much like the cylinder test, and also small expansions in the head on. flat plate tests.

\section{REFERENCES}

1. P. A. Urtiew, L. M. Erickson, B. Hayes, and N. L. Parker, "Pressure and Particle Velocity Measurements in Solids Subjected to Dynamic Loading", Published in Fizika Goreniya i Vzryva, Vol. 22, No. 5, pp. 113-126, Sept.-Oct., 1986.

2. C. F. McMillan, et. al,, "Velocimetry of Fast Surfaces at LLNL using Fabry-Perot Interferometry" Revicw of Scientific Instruments, 59)(1) Review Article Jan. 1988.

3. J. Wackerle, H. L. Stacy, "Refractive Index of Shocked Alkali Halides", 1987 Topical Conference on Shock Waves in Condensed Matter, Los Alamos LA-UR 87-2216.

4. C. M. Tarver, R. D. Breithaupt, J. W. Kury, "Current Experimental and Theoretical Understanding of Detonation Waves in Heterogeneous Solid Explosives", International Symposium on Pyrotechnics and Explosives, Beijing, China, 10/12 - 15/87. UCRL - 95462

5. L. G. Green, C. M. Tarver, and D. J. Erskine, "Reaction Zone Structure in Supracompressed Detonating Explosives", 9th Symposium (International) on Detonation, Portland, OR., Aug. 28 - Sept. 1,1989 .

6. J. W. Kury, R. D. Breithaupt, "Detonation Product Equation of State for Baratol", 9th. Symposium (International) on Detonation, Portiand, OR., Aug 27 - Sept. 1, 89. UCRL - 101761

7. W. C. Taro, et. al., "Undersianding Explosive Energetics: I The Role of Metallic Additives", 14th. Symposium on Pyrotechnics and Explosives, Burlingame, CA. Feb. 13-15, 90

8. D. R. Coosman "Optical Velocimetry Correction in Fabry Perot or Visar Measurements Taken through Cylindrically Expanding Shocked Fluids with No Dispersion" Journal of Applied Physics, Sept. 2(), 1988 UCRL 99330.

9. B. Hayes and C. M. Tarver, "Interpolation of Detonation Parameters from Experimental Particle Velocity Records", 7th. Symposium (Int.) on Detonation, NSWC MP 82-334 Naval Surface Weapons Center (1981), pp. 1029-1039.

10. H. H. Chau, et. al. "Electric gun : a versatile tool for high-pressure shock wave research," Rev, Sci. Instrum. $51,1676-1681(1980)$ 


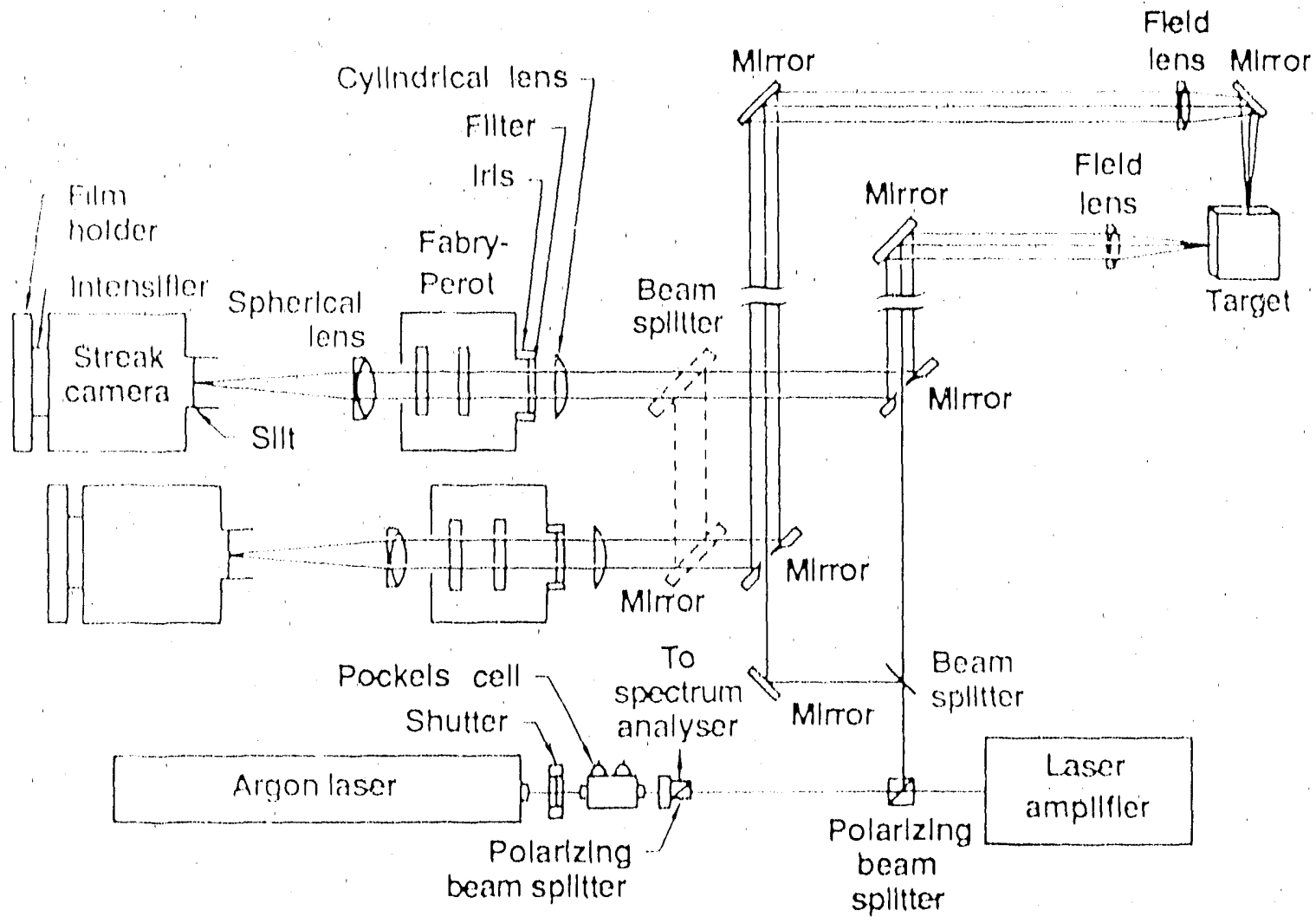

Figure 1. Layout of a Fabry-Perot experimental setup typically used at LLNL.

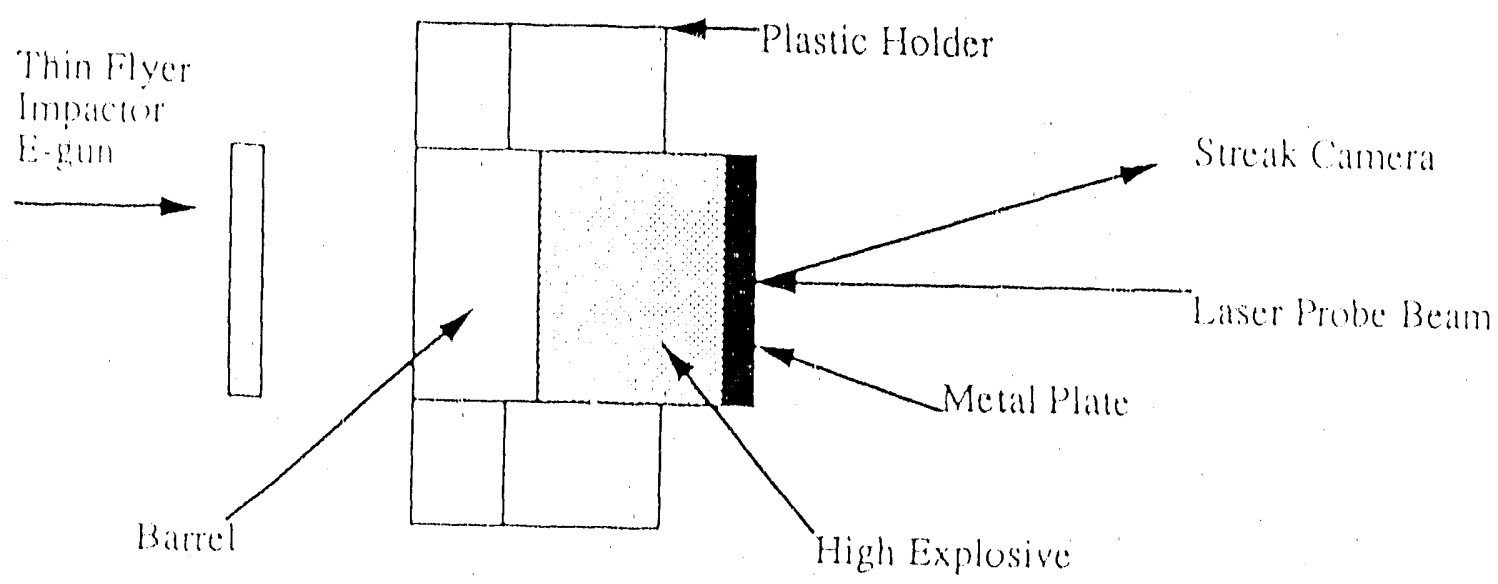

Figure 2. Flat plate experimental setup 


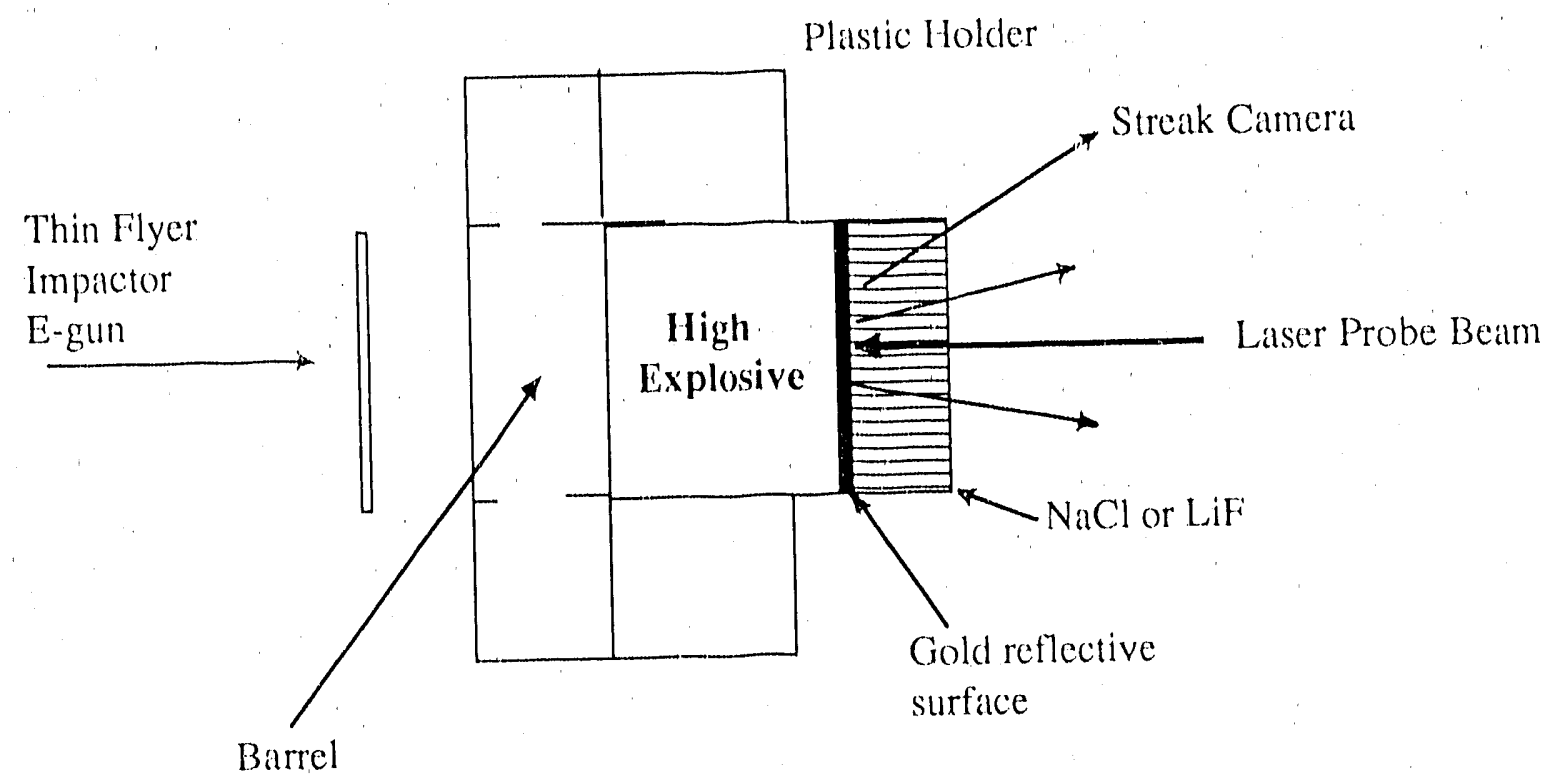

Figure 3. Particale velocity experimental setup.

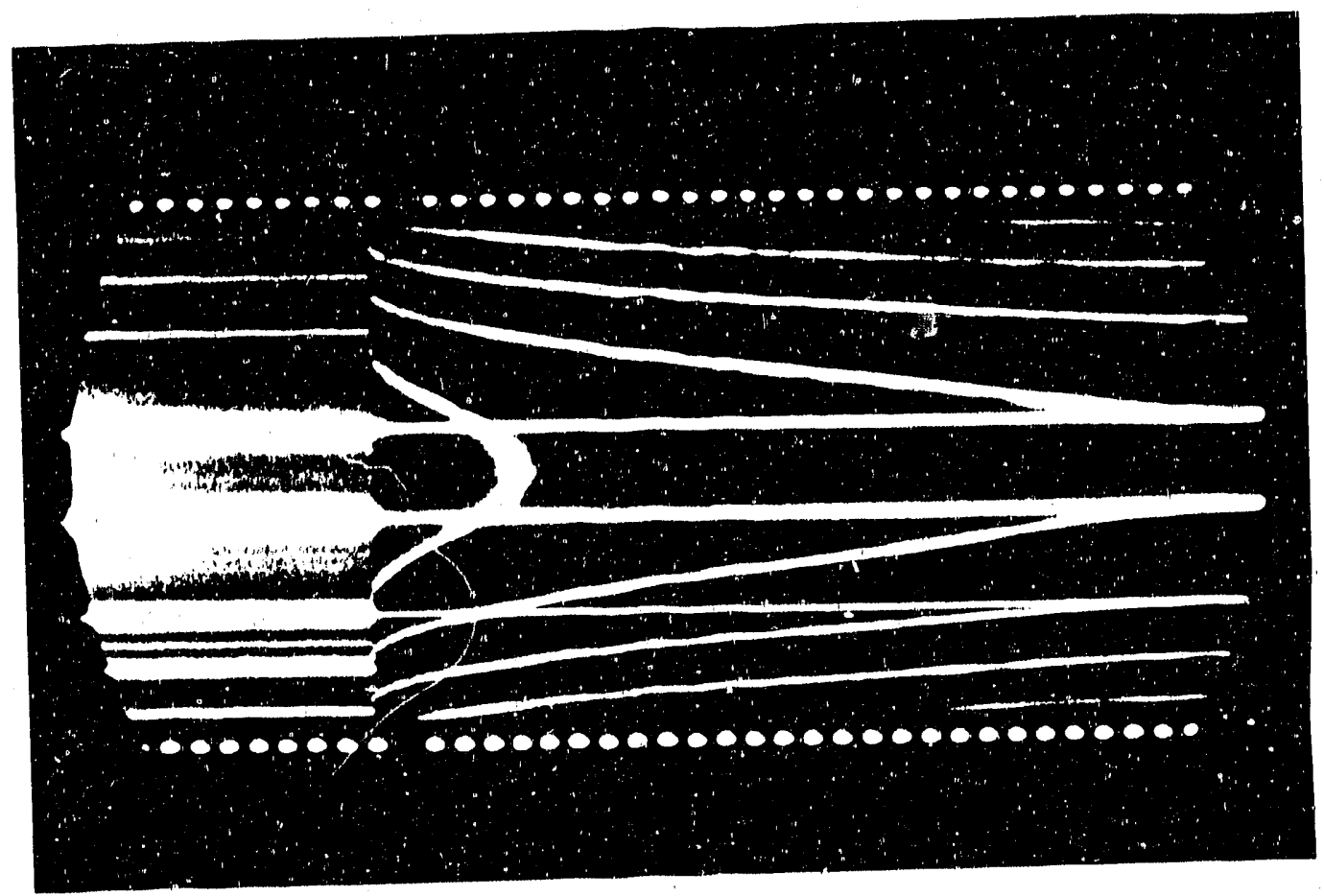

Figure 4. Particle velocity record. 


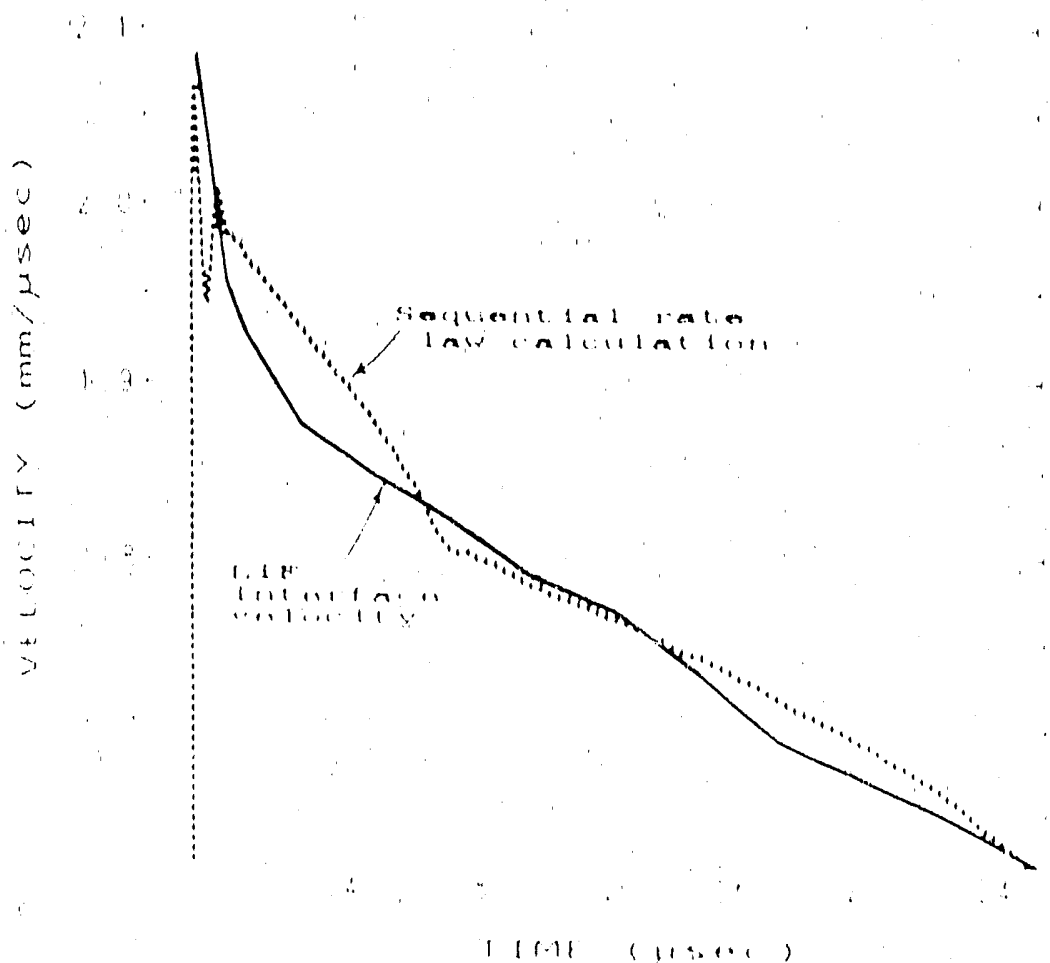

Figure 5. Two sequential rate laws were used, turst gong to $37 \mathrm{GPa}$ and then going to $34 \mathrm{GPa}$.

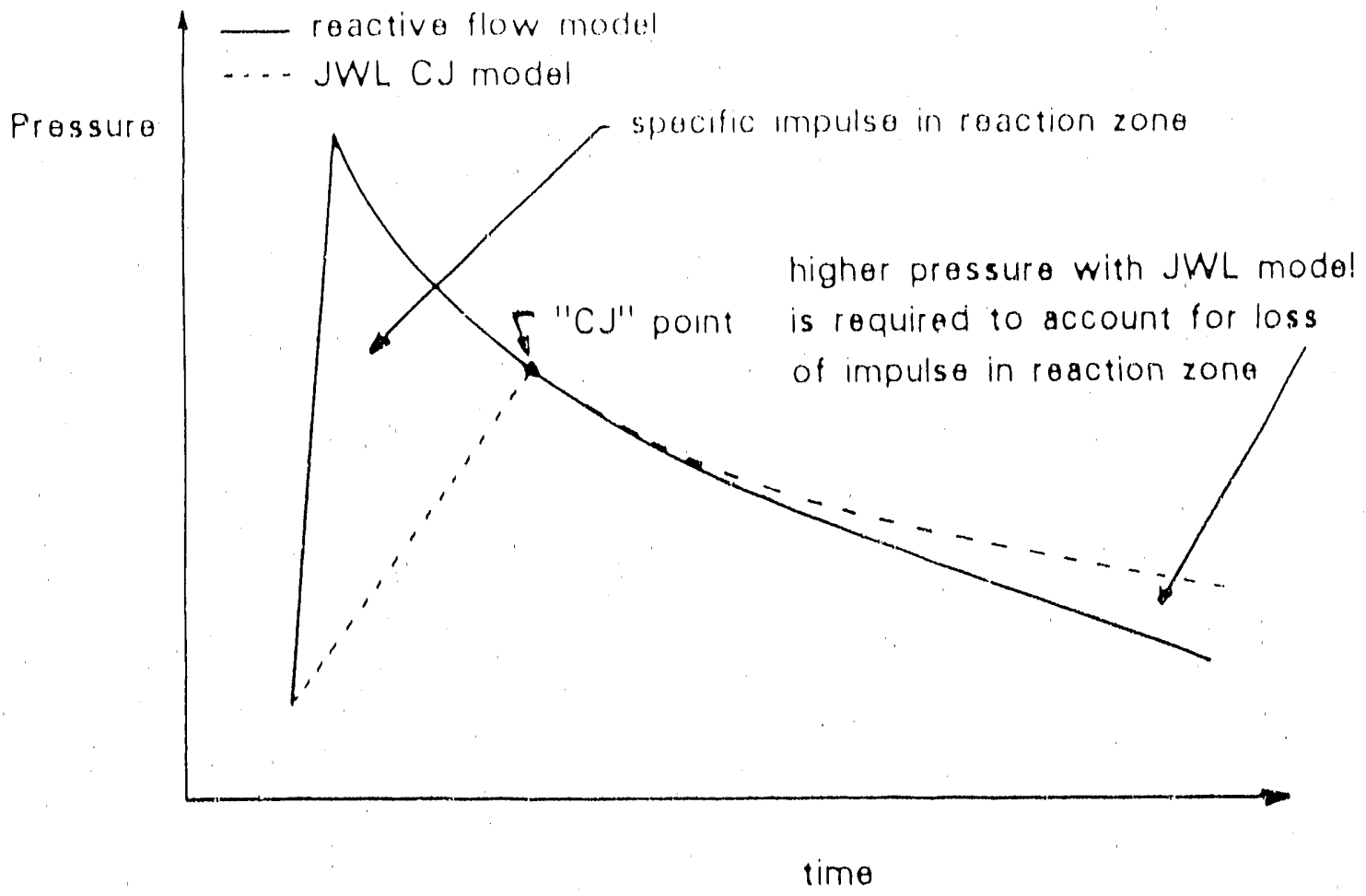

Figure 6. comparison of RF versus standard CJ prediction of pressure wave profile shows "specific impulse" in reaction zone. 

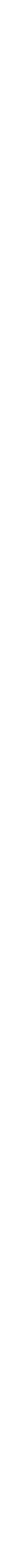
$\mid$ 